\title{
ARTRÓPODES COMO TEMA GERADOR DE UMA PRÁTICA EDUCATIVA EM UMA ESCOLA DE ARTES NO MUNICÍPIO DE PALOTINA (PR)
}

Bruna Caroline Buss ${ }^{1}$

Valéria Ghisloti lared ${ }^{2}$

Resumo: O presente trabalho é um relato de experiência que teve como objetivo analisar uma interação educativa na qual os artrópodes foram apresentados e vivenciados por um grupo de crianças em uma escola de artes no município de Palotina (Paraná). Com o intuito de sensibilizar os educandos quanto aos artrópodes, foi propiciado um espaço educativo de emergência de curiosidade, afetividade e respeito para com esses animais. A coleta de dados foi realizada por meio de observação, diário de campo e alguns materiais produzidos nos encontros. Após a triangulação e análise dos dados, emergiram quatro aspectos relevantes para o estudo, sendo eles: curiosidade; percepção da presença; biodiversidade local e sensibilização por meio dos sentidos.

Palavras-chave: Insetos; Educação Ambiental; Educação da Atenção.

Abstract: The present work is an experience report that aimed to analyze an educational interaction in which arthropods were presented and experienced by a group of children at an art school in the city of Palotina (PR, Brazil). In order to sensitize students to arthropods, an emergency educational space for curiosity, affection and respect for these animals was provided. Data collection was carried out through observation, field diary and some materials produced at the meetings. After triangulation and data analysis, four aspects relevant to the study emerged, namely: curiosity; presence perception; local biodiversity and awareness through the senses.

Keywords: Insects; Environmental Education; Education of Attention.

1 Universidade Federal do Paraná, PR. E-mail: brunacarolinebuss@gmail.com

2 Universidade Federal de São Carlos, SP. E-mail: valiared@gmail.com 


\section{Introdução}

O quadro socioambiental que caracteriza as sociedades contemporâneas revela que os impactos antrópicos sobre o meio ambiente têm tido consequências cada vez mais complexas, tanto em termos quantitativos quanto qualitativos (JACOBI, 2003). Frente a essas crises socioambientais e os possíveis riscos de suas consequências, Guimarães et al. (2009) afirmam que a Educação Ambiental surge como uma prática social para enfrentarmos estes problemas ambientais.

A concepção sistêmica que fundamenta a Educação Ambiental permite que esta reconheça a grande importância das relações existentes entre os indivíduos em sociedade e o meio ambiente em que está inserido. Essa visão não atomista nos possibilita reconhecer que a construção de conhecimento e o despertar de um olhar crítico na sociedade é muito mais importante do que o resultado focado em um indivíduo isolado (SILVEIRA; ALVES, 2008).

Diversos autores do campo argumentam sobre os vários objetivos a serem alcançados em meio à prática ambiental, como sensibilização, mobilização, informação e ação, os quais são concebidos como um processo permanente e não linear (CARVALHO; GRÜN, 2005; JACOBI, 2003). A sensibilização pode ser instigada com recursos didáticos que apresentem algum impacto emocional no indivíduo, despertando emoções e preocupações. O ser humano é um ser construtivo e criativo e quando sensibilizado, pode construir, criar, individual ou coletivamente, condições melhores de vida para si mesmo e para seus semelhantes (SCHUELTER, et al., 2001). Na mobilização e ação, busca-se orientar os indivíduos para a cooperação e envolvimento coletivo ao propor resoluções para os desafios locais. A informação é considerada indispensável para introdução de uma ideia técnica ao projeto de Educação Ambiental e a linguagem deve ser adequada segundo o público e realidade (SCHUELTER, et al., 2001).

Entre as diferentes linhas e/ou correntes endereçadas à Educação Ambiental, adotou-se, neste trabalho, uma postura (pós) crítica de Educação Ambiental em um contexto não formal, a qual é referida no décimo terceiro artigo da Política Nacional de Educação Ambiental (BRASIL, 1999). Portanto, este estudo teve como objetivo analisar uma interação educativa na qual os artrópodes foram apresentados para um grupo de educandos em uma escola de artes no município de Palotina (Paraná), buscando sensibilizá-los quanto a esses animais, propiciando um espaço educativo de emergência de curiosidade, afetividade e respeito e reflexão quanto à necessidade de conservação da biodiversidade local.

\section{Justificativa}

A elevada demanda para resolução dos problemas ambientais vem causando, também, um aumento quanto ao número de projetos em Educação Ambiental. São abundantes os projetos sobre reciclagem, hortas em escolas, arborização, compostagem, preservação do meio ambiente, entre outros. 
Porém, temáticas acerca da biodiversidade faunística, geralmente, trazem um enfoque maior em grandes animais como os vertebrados (felinos, mamíferos, aves, etc.), principalmente por serem animais "carismáticos" e sofrerem com caças ilegais e atropelamentos. Em consequência disso, muitas vezes os invertebrados acabam sendo ignorados nas práticas educativas.

Quando se faz menção aos invertebrados, um grupo muito diversificado de animais é considerado, incluindo os filos Annelida, Molusca, Cnidária, Arthropoda, entre outros. Devido a abundância e aptidão de se trabalhar com esses animais, por serem facilmente encontrados no cotidiano, optou-se pelo último como tema gerador - seguindo a perspectiva de Freire (1985) - para a presente prática educativa.

Realizando uma busca, entre os meses de setembro e outubro de 2018, com os descritores "artrópode", "arthropoda", "inseto", "insecta" e "invertebrado" em diversas revistas de Educação Ambiental foi possível observar uma escassez de trabalhos com esta temática. Outros trabalhos foram encontrados, mas eram abordados com importância para o ensino em ciências e não como temáticas geradoras de uma prática em Educação Ambiental.

Apesar de abundantes e relevantes nos processos ecológicos, os artrópodes passam despercebidos e estão geralmente associados ao medo e doenças. Segundo Jara (1996), esses animais são vistos como desnecessários, pestes ou pragas do mundo atual. Seus valores estão sempre associados ao medo, asco ou doenças e são insuficientemente investigados no que se refere ao modo como são percebidos, classificados, conhecidos e utilizados pela população humana.

Os insetos (grupo dentro dos artrópodes), apesar de compor o mais abundante e diverso grupo dentre todos os animais, não são muito carismáticos. Assim, segundo Miranda e Figueiredo (2009), a representação de inseto é geralmente concebida como algo "ruim", "sujo", "nojento" ou "insignificante" e outros atributos igualmente pejorativos. Nesta representação construída pela sociedade, são tomados como referência os animais que convivem com o ser humano dentro do ambiente urbano, como: baratas, moscas, aranhas, mosquitos, vetores de doenças ou que possuam substâncias irritantes, alergênicas ou peçonhas. Nos ambientes rurais, são destacados aqueles considerados como pragas de grandes culturas (MIRANDA; FIGUEIREDO, 2009).

As interações possíveis desses animais e sua importância na natureza são, no entanto, muito maiores do que essas relações e representações. É necessário ressaltar a importância dos artrópodes como agentes participantes de vários processos tanto benéficos - como polinização, controle biológico, manutenção do meio, decomposição, etc. - quanto maléficos, além de defini-los como principais componentes da biota dos ecossistemas, merecendo, ao 
menos, respeito por sua grande capacidade adaptativa e sucesso inegável na colonização dos ambientes terrestres. (MIRANDA; FIGUEIREDO, 2009).

Para Ferraris (2008), é comum que crianças e adolescentes tendam a diminuir o medo de animais domésticos e desenvolvam o pavor de insetos e outros invertebrados ao longo do crescimento. Uma possibilidade de superar essa aversão é o processo de familiarização e sensibilização, na qual a aprendizagem se dá a partir da curiosidade, de um processo reflexivo, de um envolvimento afetivo, que possivelmente, possa levar a conservação (MORALES, 2000).

Thiemann e Oliveira (2013) acreditam que as pessoas entendem e atribuem valores distintos à biodiversidade. No estudo supracitado, as autoras elaboraram categorias de sentido para compreender as possíveis relações com a biodiversidade. Entre as categorias elaboradas pelas autoras, está a categoria Oculta, na qual "a biodiversidade aparece como algo que, apesar de estar ao redor, não é visto, e por isso é preciso direcionar o olhar para ela" (THIEMANN; OLIVEIRA, 2013, p. 120). Portanto, a preocupação deste estudo foi desvelar esta categoria, e com isso, (re)significar a percepção sobre os artrópodes.

\section{Procedimentos Metodológicos}

\section{Contexto do estudo}

O relato de experiência caracteriza-se como sendo de cunho qualitativo. Os trabalhos pautados nessa modalidade de pesquisa têm por princípio a aceitação dos aspectos subjetivos de um contexto, cujos resultados não passam por um processo de generalização, e sim por um processo de transferibilidade (RODRIGUES, et al., 2007). Segundo Yin (2016), a técnica comumente utilizada para estudos de campo de cunho qualitativo é a observação participante, a qual coloca o pesquisador como integrante da comunidade que está sendo abordada a temática. Whyte (2005) afirma que a observação participante supõe a interação pesquisador/ pesquisado e implica no saber ouvir, ver e respeitar o ponto de vista dos participantes.

Para o desenvolvimento desse trabalho, foram realizados cinco encontros de aproximadamente duas horas entre agosto e outubro de 2018 com uma turma de cinco alunos, com idades entre nove e doze anos, em uma escola de artes municipal, localizada em uma área verde do município de Palotina (região oeste do Paraná). A professora responsável pela escola autorizou e participou ativamente do desenvolvimento do projeto. Segundo Yin (2016), para realizar pesquisas qualitativas em instituições públicas como a escola, é necessária permissão das autoridades escolares, bem como dos responsáveis legais dos educandos. Portanto, foi enviado um termo de consentimento livre e esclarecido para os responsáveis legais dos alunos participantes, os quais concordaram com o desenvolvimento da proposta educativa.

Como já citado, a escola estava localizada em uma área verde urbana, o 
didáticos do trabalho. Atualmente, a maior parte das pessoas vivem nas cidades, muitas delas têm pouco contato com ambientes naturais e com as espécies silvestres nativas (MILLER, 2005). Desta forma, as áreas verdes urbanas configuram-se como espaços educadores que contribuem para o acesso à biodiversidade local, sensibilização e mobilização da população para a conservação. Kunieda (2010) explica que o termo espaço educador é uma metáfora utilizada para ressaltar o protagonismo do espaço e de suas estruturas no processo educativo, funcionando como um agente ativo e não apenas como um cenário onde o ensino e a aprendizagem ocorrem. Segundo a autora, ele também é um espaço simbólico e vivencial e a experiência que as pessoas desenvolvem com cada espaço é importante no processo educativo.

\section{Recursos didáticos}

Foram utilizados vários instrumentos para sensibilizar os educandos quanto à temática abordada, dentre elas o uso de fotografias, material biológico, recursos visuais e modelagem. Nesse tópico, a importância e objetivo de cada um são brevemente apresentados.

A fotografia é um instrumento midiático que alia informação à arte e, portanto, revela-se como possibilidade de provocar a sensibilidade humana (ARAUJO; FERNANDES, 2010). A Educação Ambiental e a fotografia compõem um terreno fértil na elaboração de uma nova relação ser humano e natureza, na consolidação de uma consciência ecológica que reconheça a importância e o valor de todas as formas de vida e na responsabilidade da formulação de um novo pensamento coletivo e planetário (ARAUJO; FERNANDES, 2010).

Muito se tem discutido sobre o uso de material biológico como recurso didático para as práticas educacionais, pois esta estratégia tende a aproximar o indivíduo com os organismos que se pretende trabalhar, além de ser, segundo Rodrigues et. al. (2008), uma atividade prazerosa aliada à efetividade dos objetivos educacionais. Portanto, pode ser considerado um excelente instrumento educacional quando se almeja mobilizar o processo de significação e sensibilização do conteúdo abordado, justificando a escolha pelo uso de tal recurso.

Os modelos didáticos, segundo Cysneiros-Matos et al. (2009), são representações confeccionadas a partir de um material concreto, podendo ser estruturas ou partes de processos biológicos. Assim, os modelos correspondem a um sistema figurativo que reproduz a realidade de forma especializada e concreta, tornando-a mais compreensível ao aluno (JUSTINA; et al., 2006). Este tipo de metodologia busca recuperar a importância do tato, a consciência do próprio corpo, o toque e a sensibilização do indivíduo (SILVA, 2006).

Utilizaram-se também de estratégias de sensibilização por meio dos sentidos, no caso, o paladar, tato e visão. Foi entregue aos educandos salada de frutas e mel, alimentos produzidos por meio de serviços faunísticos como 
polinização, podendo trabalhar a relação do papel ecológico, econômico e social desses animais. A percepção ambiental envolve o organismo e o ambiente e é construída tanto pelos órgãos dos sentidos - percepção como sensação - como por elaborações mentais oriundas de experiências individuais, associações conceituais e contextos socioculturais - percepção como cognição (HOEFFEL; FADINI, 2007). Dessa forma, a sensação é apreendida ao mesmo tempo em que a elaboração cognitiva também atua na forma como ativamos as sensações, sendo esses aspectos indissociáveis.

Outros recursos didáticos aplicados foram os jogos, vídeos, animações, moldes, maquetes e caminhadas na área verde como alternativas para maior interação dos participantes. Antunes et al. (2011) dizem que são estratégias que podem ser utilizadas para diferentes abordagens na escola, o que segundo Moran (2005), pode funcionar como meio de despertar a atenção e curiosidade para novos temas. O Quadro 1 sintetiza quais recursos foram aplicados em cada encontro:

Quadro 1: atividades desenvolvidas durante os cinco encontros.

\begin{tabular}{|c|l|l|}
\hline ENCONTRO & \multicolumn{1}{|c|}{ ATIVIDADE REALIZADA } & \multicolumn{1}{c|}{ RECURSOS DIDÁTICOS } \\
\hline $\mathbf{1}$ & $\begin{array}{l}\text { Apresentação do projeto. } \\
\text { Trabalhado a temática: "Quem são } \\
\text { os artrópodes?". }\end{array}$ & $\begin{array}{l}\text { Material biológico como aranhas, } \\
\text { escorpião, lacraia, centopeia, camarão } \\
\text { e um insetário. } \\
\text { Apresentação em projetor multimídia. }\end{array}$ \\
\hline \multirow{2}{*}{$\mathbf{3}$} & $\begin{array}{l}\text { Revisão do encontro anterior. } \\
\text { Busca por artrópodes no bosque } \\
\text { para fotografias. } \\
\text { Trabalhado a temática: "Habitat e } \\
\text { abundância". } \\
\text { Análise das imagens. }\end{array}$ & $\begin{array}{l}\text { Apresentação em projetor multimídia. } \\
\text { Vídeos sobre a ecdise. } \\
\text { Fotografias. }\end{array}$ \\
\hline $\mathbf{3}$ & $\begin{array}{l}\text { Trabalhado a temática: "Importância } \\
\text { dos artrópodes, impactos que geram } \\
\text { a redução populacional e medidas } \\
\text { de prevenção". }\end{array}$ & $\begin{array}{l}\text { Degustação de frutas e mel. } \\
\text { Maquetes de fragmentação da } \\
\text { paisagem. } \\
\text { Apresentação em projetor multimídia. }\end{array}$ \\
\hline $\mathbf{4}$ & $\begin{array}{l}\text { Trabalhado a temática: "artrópodes } \\
\text { peçonhentos". }\end{array}$ & $\begin{array}{l}\text { Modelagem com massinha. } \\
\text { Apresentação em projetor multimídia }\end{array}$ \\
\hline $\mathbf{5}$ & $\begin{array}{l}\text { Encerramento do projeto. } \\
\text { Revisão de todos os encontros. } \\
\text { Atividade de avaliação. }\end{array}$ & $\begin{array}{l}\text { Trecho do filme "Vida de Inseto". } \\
\text { Apresentação em projetor multimídia. } \\
\text { Desenhos e textos. }\end{array}$ \\
\hline
\end{tabular}

FONTE: A autora (2018).

\section{Coleta de dados}

Existem diversas técnicas de coleta de dados na pesquisa qualitativa e sua escolha está diretamente relacionada ao objetivo e contexto da investigação. Entre as mais amplamente aplicadas estão: a observação, questionários, entrevistas e análise de documentos. O estudo objetivou analisar a implementação de uma intervenção, portanto, os instrumentos escolhidos foram a observação e registros produzidos durante a prática educativa. 
Segundo Yin (2016), a coleta de dados por meio da observação leva em questão os gestos das pessoas, interações sociais, ações, cenas e também o ambiente físico. Para o autor, observar é um método valioso de coletar dados, "porque o que você vê com os seus olhos e percebe com seus sentidos, não é filtrado pelo que os outros podem ter relatado a você" (YIN, 2016, p. 127).

Segundo Ludke e André (1986), a observação possibilita um contato pessoal e estreito do pesquisador com o fenômeno pesquisado, o que apresenta uma série de vantagens, como por exemplo, permitir que o observador esteja próximo da perspectiva dos sujeitos. Em consonância, Minayo (1994) afirma que a importância desta técnica de coleta de dados reside no fato de possibilitar a apreensão de uma variedade de situações ou fenômenos que não são obtidos por meio de perguntas, uma vez que, observa-se diretamente na própria realidade. Paralelamente às observações, surge à necessidade de registrar os dados observados, e para tal, Minayo (1994) destaca o uso do diário de campo no qual são descritas as percepções, angústias, questionamentos e informações que não são obtidas através da utilização de outras técnicas.

Além da observação, durante a interação educativa, foram produzidos documentos, os quais também se constituíram como corpus de análise do trabalho. Os documentos foram produzidos de forma gradual e contínua durante a intervenção educativa, os quais representam as evidências da aprendizagem e difere de outros instrumentos de coleta de dados, pois oportuniza a reflexão sobre as mudanças ao longo do curso. Tais documentos foram produzidos pelos próprios participantes em formato de iconografia, que compreende a documentação por imagem (gravuras, estampas e desenhos) e pela escrita. Segundo Yin (2016), estes objetos podem ser valiosos para o estudo qualitativo ao enriquecer o corpus de análise por se configurarem como mais uma fonte de compreensão do fenômeno estudado.

\section{Resultados de Discussão}

Segundo Yin (2016), a análise de dados qualitativos toma como base cinco fases, que não ocorrem de maneira linear. A primeira fase é de compilação dos materiais coletados para formar uma base de dados, a qual exige uma organização cuidadosa e metódica dos dados originais. A segunda, decomposição dessas informações, podendo envolver procedimentos de decodificação formal. A terceira fase é então seguida pela recomposição de dados e se beneficia da capacidade que o pesquisador tem de identificar os padrões emergentes da pesquisa. Na quarta fase, é realizada a interpretação a qual envolve o uso de material decomposto para criar uma narrativa. E por fim, a quinta e última fase pode ser concebida como a conclusão, a qual exige a uma visão holística de todo o estudo, tomando como base as interpretações das fases anteriores. 
A partir da releitura do diário de campo e dos outros registros, emergiram quatro aspectos que serão enfoque da discussão: (1) curiosidade, (2) percepção da presença, (3) biodiversidade local, (4) sensibilização por meio dos sentidos. Os aspectos identificados não são categorias isoladas, sendo consideradas como complementares e intercambiáveis. A Figura 1 sistematiza como foram realizados os procedimentos metodológicos da presente pesquisa. $\mathrm{Na}$ sequência, os dados serão apresentados e discutidos seguindo esses quatro elementos emergentes.

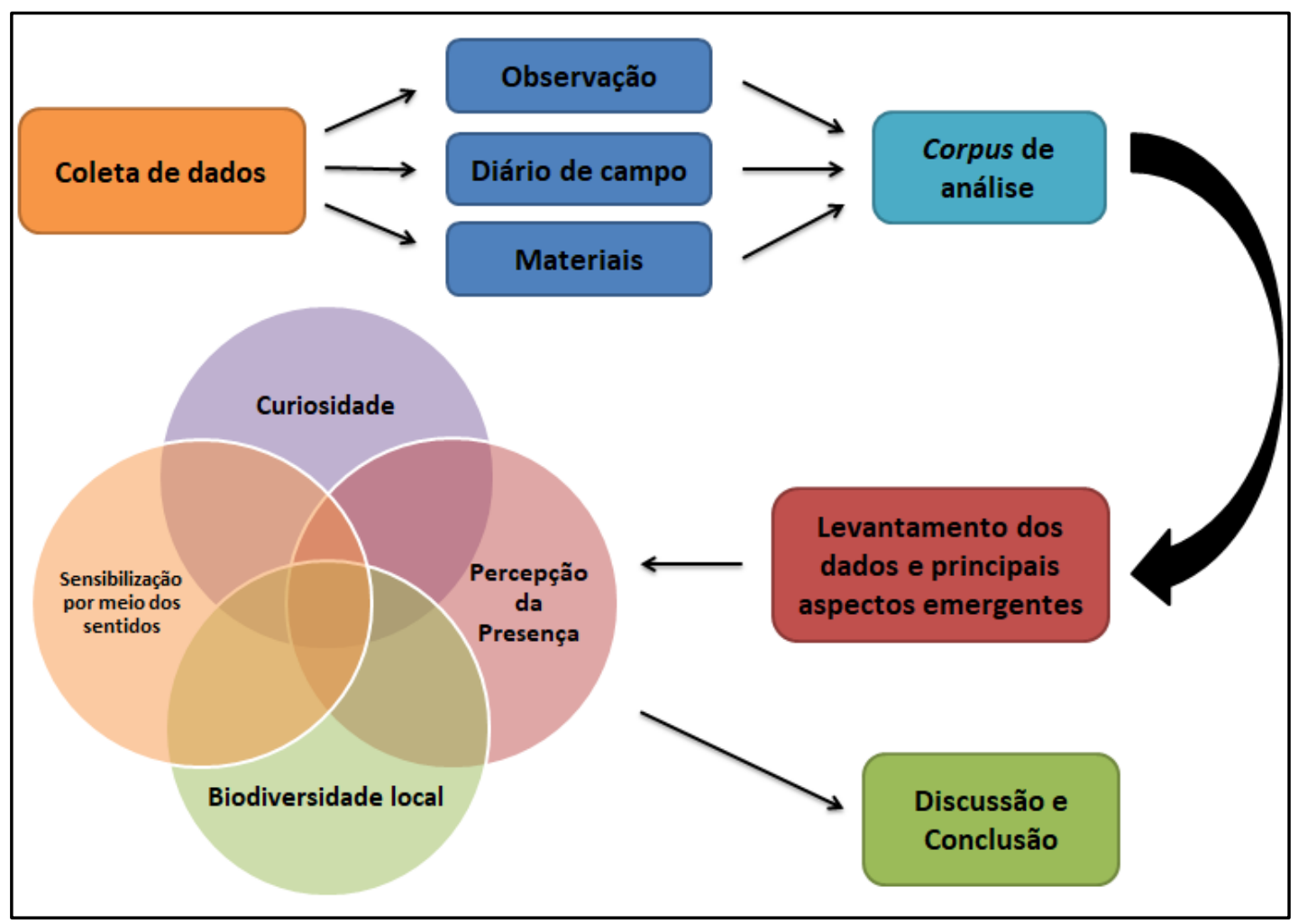

Figura 1: Esquema dos procedimentos metodológicos.

Fonte: As autoras, 2018.

\section{Curiosidade}

Foi possível observar positivamente o despertar da curiosidade das crianças sobre os artrópodes ao longo dos encontros, principalmente por meio das diversas perguntas feitas por eles. Os alunos perguntaram sobre a reprodução das formigas, sobre a camuflagem de alguns animais, sobre 0 comportamento das abelhas ${ }^{3}$ e outras curiosidades quanto às relações ecológicas desses animais. 
Sobre isso, Freire (1996) diz que a reflexão é o movimento realizado entre o fazer e o pensar e entre o pensar e o fazer. Nesta direção, a reflexão surge da curiosidade. Essa curiosidade inicialmente é considerada ingênua, porém com o exercício constante, a curiosidade se transforma em crítica epistemológica. Segundo o autor, esta curiosidade epistemológica é construída pelo exercício crítico da capacidade de aprender. $E$ é a curiosidade que se opõe à curiosidade ingênua que caracteriza o senso comum. A busca por conhecimento evidencia, portanto, a saída da "curiosidade ingênua" para uma sistematização problematizadora ("curiosidade epistemológica") sobre esses animais, buscando conhecer mais sobre seus hábitos, importância, características e interações ecológicas, como se observou nas perguntas das crianças participantes.

Outro momento da prática na qual foi verificada a curiosidade dos participantes quanto à temática abordada, foi no momento da atividade de modelagem, pois pediam a todo o momento como eram as características morfológicas dos animais que modelavam (Figura 2).

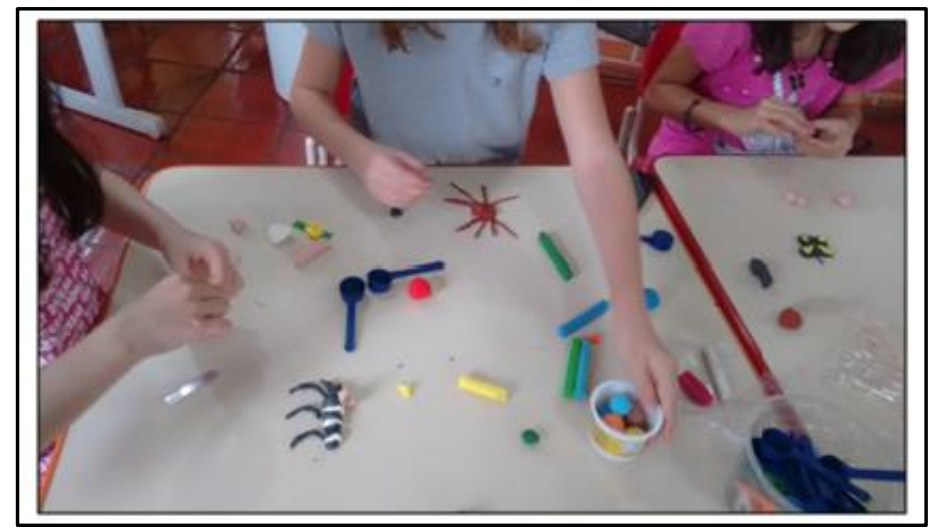

Figura 2: Educandos desenvolvendo a atividade de modelagem dos artrópodes.

Fonte: Acervo pessoal, 2018.

A curiosidade muitas vezes faz o indivíduo (re)significar o medo sobre o desconhecido (FERRARIS, 2008) e isso pôde ser constatado em outra atividade desenvolvida no projeto. Ao levar alguns artrópodes preservados em álcool, como aranhas, escorpiões, centopeias e camarão, as crianças, em um primeiro momento, demonstraram um sentimento de repulsão por estes animais, e após conversa e manipulação dos materiais didáticos, pediram permissão para pegar a aranha na mão (Figura 3 ). Identificou-se uma resposta afetiva das crianças pela aproximação com os mesmos. Um dos objetivos da Educação Ambiental é a sensibilização e trabalhar com este medo e repúdio sentido pelas crianças por esses animais torna-se uma atividade relevante para a conservação da biodiversidade. Portanto, a partir do momento em que as crianças participantes iniciaram o processo de familiarização e de descobrimento sobre estes animais 
nos encontros, simultaneamente, demonstraram um deslocamento do sentimento de fobia para curiosidade e respeito.

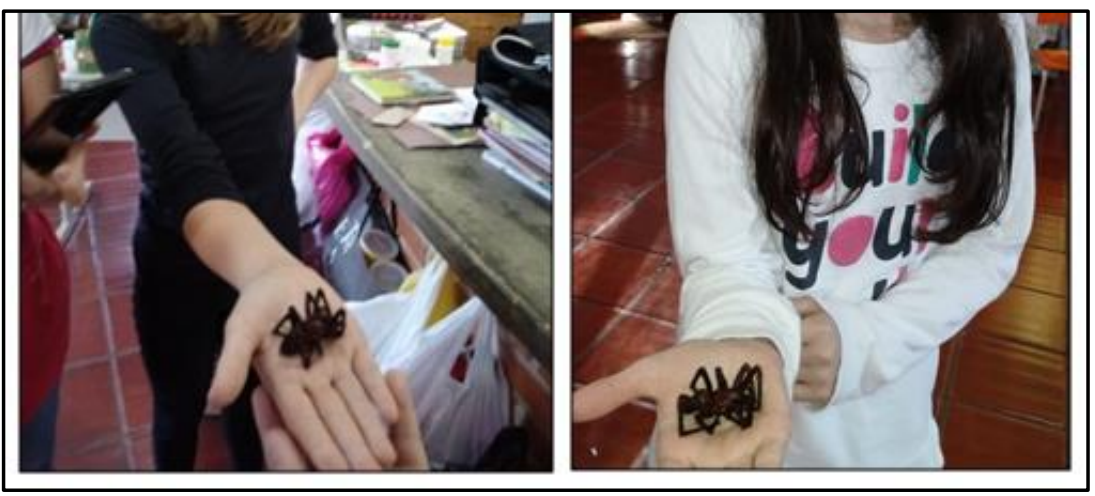

Figura 3: Educandas segurando um exemplar de aranha.

Fonte: Acervo pessoal, 2018.

As vivências dos encontros foram apropriadas pelas crianças as quais relembraram, em outros momentos, o que foi abordado. Isso pôde ser observado em uma das avaliações: quando solicitado que desenhasse algo sobre os encontros, uma das educandas fez referência a uma das curiosidades levantadas no processo educativo, a camuflagem de alguns animais (Figura 4).

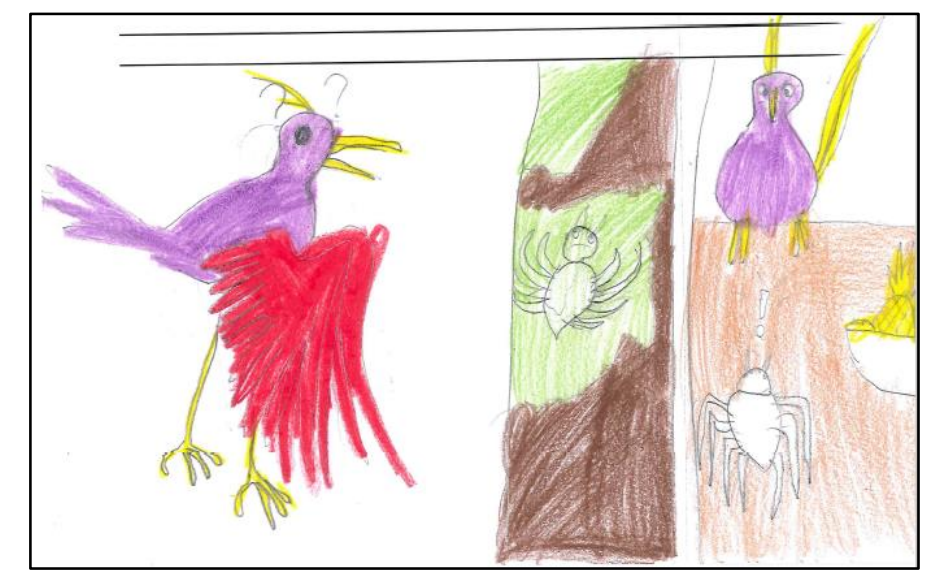

Figura 4: Desenho de uma das educandas sobre os encontros. Fonte: Acervo pessoal, 2018.

No desenho, a criança representa um pássaro que não encontra a aranha que está camuflada na árvore por apresentar coloração semelhante à árvore e, em outro momento, desenha o mesmo pássaro localizando facilmente outra aranha com coloração corporal diferente da superfície (mesa) em que ela se encontra. Essa situação foi observada, também, durante a busca por artrópodes no bosque em que a escola está localizada. Uma aranha foi encontrada em uma árvore com certa dificuldade justamente pelo fato de a mesma apresentar coloração corporal semelhante a árvore em que estava. 


\section{Percepção da presença}

Quanto ao objetivo de desvelamento da biodiversidade dos artrópodes, foi identificado uma (re)significação no olhar para com a percepção da presença desses animais no cotidiano, principalmente, por meio de relatos dos alunos. Em um comentário, uma aluna diz que passou a ver mais insetos em sua casa após os encontros, outra relata que passou a observar quais animais habitavam sua residência. $O$ desenvolvimento dessa intervenção educativa permitiu que os indivíduos passassem a perceber estes animais que muitas vezes passavam despercebidos.

O uso de fotografias como recurso didático para Educação Ambiental propiciou uma resposta sensorial quanto à percepção, pois instigou a busca por artrópodes no cotidiano dos participantes, fazendo com que os mesmos se atentassem quanto à ocorrência destes no meio em que vivem (Figura 5).

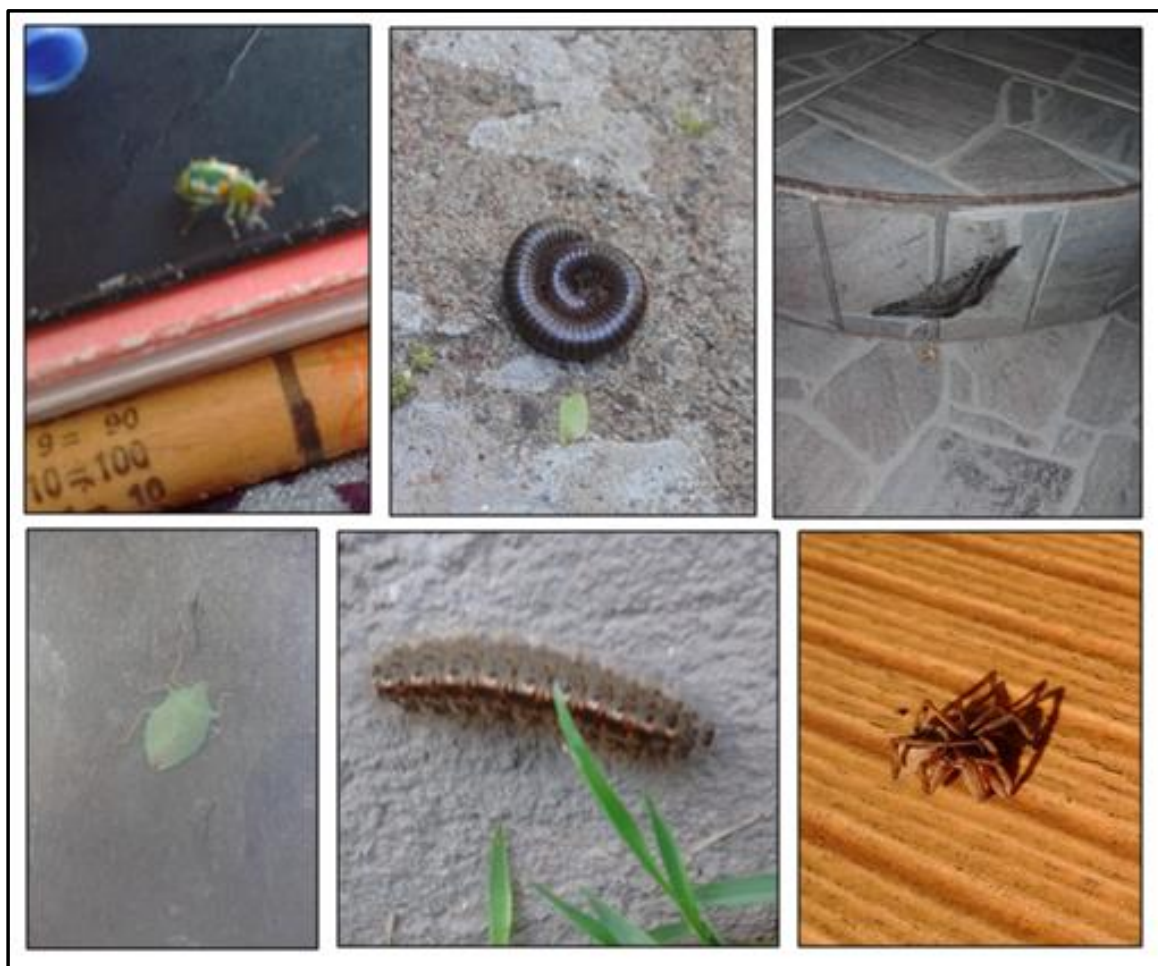

Figura 5: Imagens de artrópodes registradas pelos educandos em suas residências. Fonte: Educandos participantes do projeto, 2018.

Para ressaltar a atividade de busca por estes animais, foi realizado o passeio pelo bosque (Figura 6), atividade extremamente produtiva, visto que foram encontrados diversos artrópodes. Em trecho do diário de campo: "observamos indivíduos de todos os grupos internos de artrópodes, exceto os crustáceos, devido à localidade. Encontramos centopeias, besouros, moscas, mosquitos, borboletas, percevejo, formigas, cupins, aranhas, entre outros. Os 
insetos foram os mais observados, devido a sua grande abundância e, também, modo de vida. Encontramos fases imaturas, como exúvia de cigarra e casulos de borboletas".

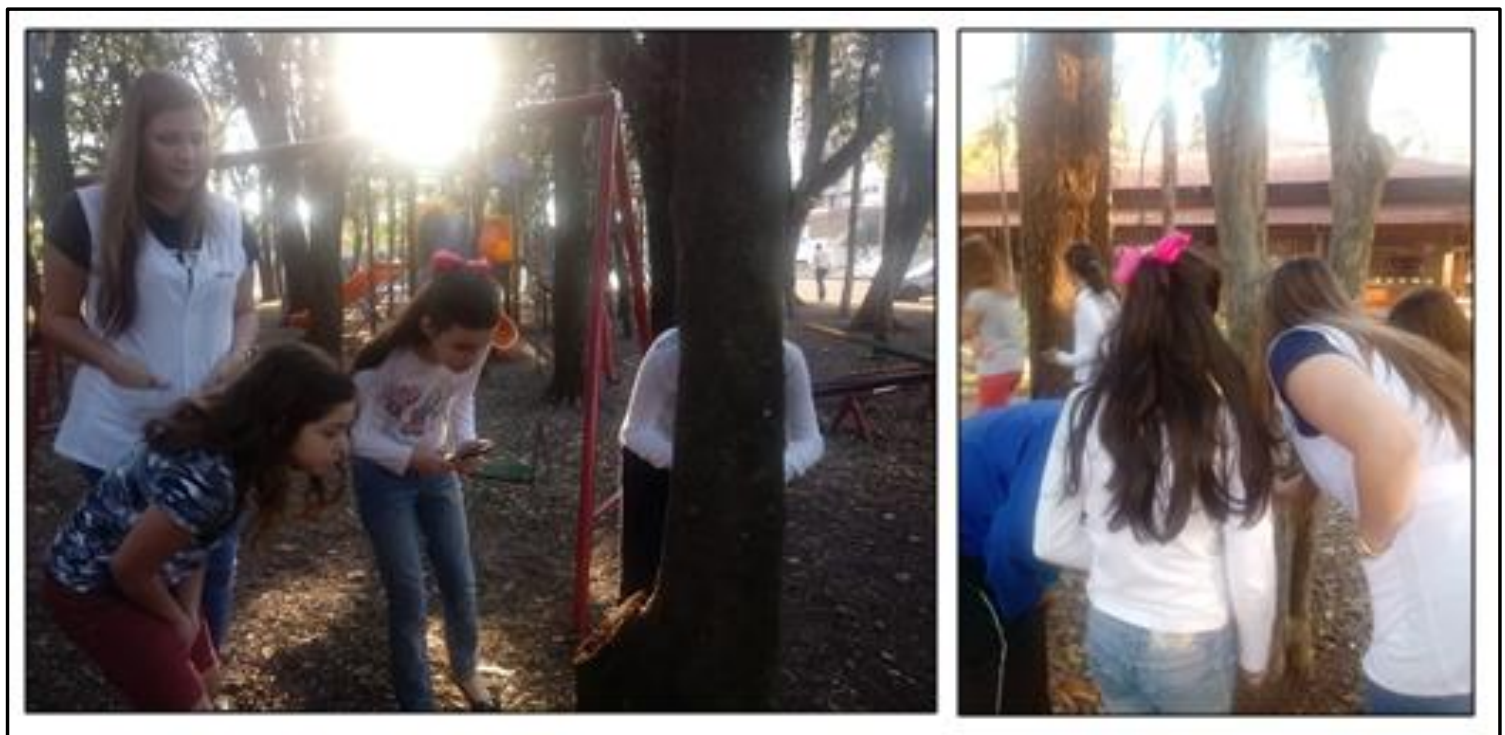

Figura 6: Busca por artrópodes no bosque:

Fonte: Professora da Escola de Artes, 2018.

Sobre isso, Ingold (2010) afirma que o processo de redescobrimento dirigido é transmitido mais corretamente pela noção de mostrar, ou seja, ao mostrar alguma coisa a alguém é fazer esta coisa se tornar presente para ela, de modo que essa possa apreendê-la diretamente, seja olhando, ouvindo ou sentindo. Portanto, não necessariamente mais invertebrados (artrópodes) começaram aparecer nas residências dos educandos participantes e, sim, os mesmos passaram a reparar mais nesses animais.

Assim, além de curiosidades, os educandos trouxeram relatos do cotidiano e experiências vividas por eles e/ou familiares, que viram insetos 'estranhos', outros que pousavam em sua cabeça, na mão, ou outra parte do corpo, comentaram que viram nuvens em forma de insetos e se lembraram dos encontros. Outro aluno comentou sobre seu tio que estava limpando o lote e encontrou escorpiões. Esses e muitos outros relatos evidenciam que a percepção da presença desses animais no cotidiano dos educandos está sendo estimulada.

Ingold (2010) chama esse processo de educação da atenção, que traz a percepção como uma atividade de todo o organismo em um ambiente, favorecendo o desenvolvimento de uma psicologia ecológica. Para o autor, não é por meio da absorção de representações mentais ou esquemáticas para organizar as sensações corporais que nós aprendemos, mas sim, através de uma sintonia ou sensibilização de todo o nosso sistema perceptivo, incluindo o cérebro e os demais órgãos receptores junto com suas conexões neurais e musculares, com aspectos característicos do meio ambiente. Para defender 
esse conceito, Ingold (2010) se pauta nas teorias do psicólogo James Jerome Gibson (1979) ao citar a metáfora de que o sistema perceptivo do praticante habilidoso ressoa com as propriedades do ambiente.

A educação da atenção equivale ao processo de afinação do sistema perceptivo, assim, ao longo do desenvolvimento, a história das relações de uma pessoa com o seu ambiente está envolvida em estruturas específicas de atenção e resposta, neurologicamente fundamentadas (INGOLD, 2010, p.23).

\section{Biodiversidade local}

Para estimular o desvelamento da categoria "oculta", mencionada anteriormente, foi necessário levar em consideração que, nos dias de hoje, boa parte das pessoas moram em centros urbanos e a maioria delas não possui contato com ambientes naturais e consequentemente com as espécies silvestres nativas, sendo elas da fauna ou flora (MILLER, 2005). Isso faz com que se conheça pouco sobre a biodiversidade local (GALHEIGO; SANTOS, 2009). Dessa forma, é importante procurar por espaços ou instituições que possuem características que contribuam na sensibilização e mobilização da população para a conservação da biodiversidade (THIEMANN, 2013). Portanto, o bosque em que a escola de artes está localizada foi extremamente importante para a efetividade do projeto educacional, pois permitiu o contato dos alunos participantes com a fauna local.

A proposta de desenvolver nos encontros a biodiversidade encontrada no município foi delineada com o intuito de possibilitar discutir as principais ameaças que estas podem estar sofrendo. Nesse sentido, foi levantada uma questão importante sobre o "desaparecimento" de algumas espécies de abelhas, principalmente a que poliniza o maracujá (vernáculo: mamangava). Pôde ser observada uma grande preocupação por parte dos educandos quanto à importância dos insetos para a produção de frutas e, por conta disso, fizeram diversas perguntas sobre como proceder para evitar a extinção desses animais.

Além disso, na avaliação, duas alunas relembraram a importância dos artrópodes: eu gostei porque não sabia que sem os artrópodes não teria vida e conhecemos mais sobre os artrópodes que sem eles não haveria vida no planeta, destacando o papel destes animais para o meio ambiente, como a polinização para a produção de frutos, para a regulação da cadeia trófica, como decompositores, entre outros papéis ecológicos (Figura 7). 


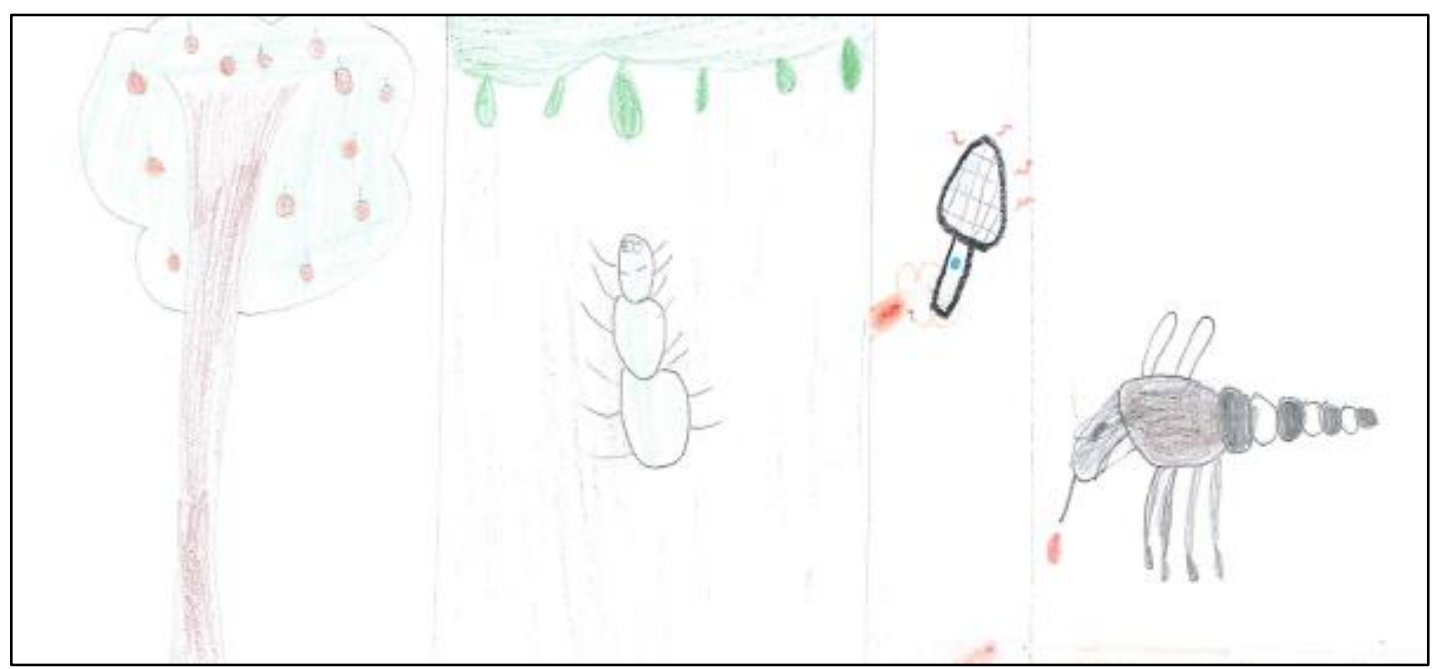

Figura 7: Avaliação de uma aluna participante do projeto.

Fonte: Educanda participante do projeto, 2018.

\section{Sensibilização por meio dos sentidos}

O estudo abordou intencionalmente estratégias de sensibilização quanto à temática abordada, e uma dessas foi à estimulação por meio dos sentidos. Segundo Goldschmidt et al. (2008), a percepção de mundo, se dá por meio dos sentidos sensoriais (audição, tato, paladar, olfato e visão) em um processo sinestésico, o qual tem relação direta com a atribuição de significado e a aprendizagem. Nessa perspectiva, o corpo imerso no ambiente, em sua integralidade, faz parte da educação da atenção (INGOLD, 2010), conceito que se opõe a dicotomia entre corpo-mente e sujeito-objeto.

Ao instigar o paladar dos educandos por meio da degustação de frutas e mel (Figura 8), a prática de modelagem (FIGURA 2) trabalhando com o tato e também a busca por artrópodes aguçando a visão, buscou-se desenvolver a sensibilização das crianças com esses animais sob a perspectiva de corpo engajado no mundo.

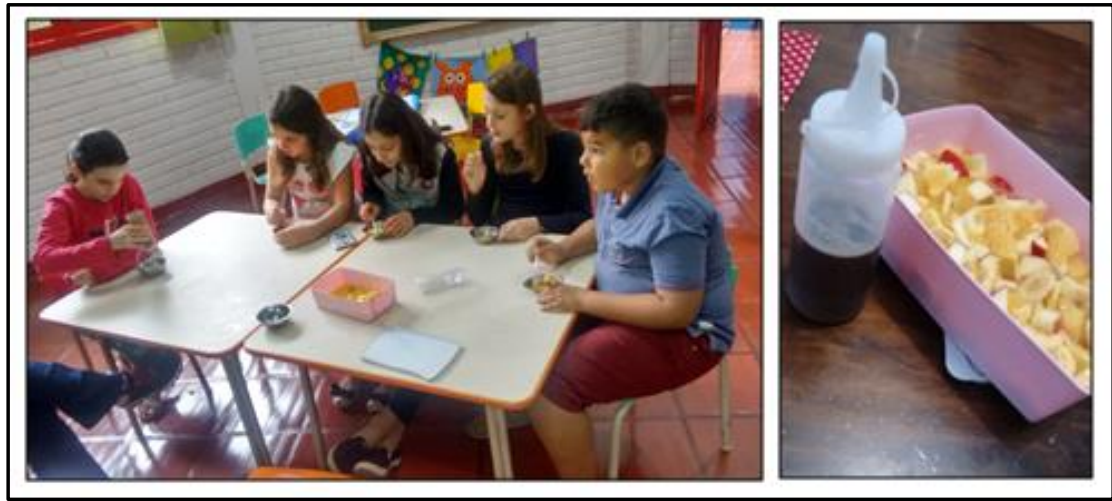

Figura 8: Encontro com degustação de mel e frutas.

Fonte: Acervo pessoal (2018). 
Tafner e Fischer (2004) acreditam na ligação do corpo com o conhecimento, porque a ação é mediada pelo corpo e ativa os demais sentidos além do visual e do auditivo. O corpo, portanto, é um canal de convergência sensorial, podendo ser compreendido como um pilar da cognição no âmbito único de experimentar o conhecimento. A Educação Ambiental tem entre seus objetivos o desvelamento da biodiversidade e complexidade da problemática ambiental para a construção de novos conhecimentos, novos olhares e, consequentemente, uma nova relação para com os seres humanos e não humanos (fauna, flora, rios, matas, etc.).

\section{Conclusões}

Percebe-se por meio deste estudo, que apesar da escassez de trabalhos abordando a temática "artrópodes", os mesmos podem ser considerados excelentes temas geradores para práticas em Educação Ambiental, pois são significativos para a educação quando se almeja despertar a sensibilização para a biodiversidade local ou regional. Os conceitos da educação da atenção de Timothy Ingold e curiosidade ingênual curiosidade epistemológica de Paulo Freire subsidiaram a compreensão do fenômeno estudado, desvelando o quanto essas práticas não são ingênuas e devem ser incorporadas no currículo das instituições seja no âmbito formal ou não formal.

Em relação à efetividade deste projeto educacional, deve-se ressaltar a liberdade de trabalhar em um contexto não formal de educação, na qual não há necessidade de seguir rigorosamente referências pedagógicas estabelecidas por órgãos federais ou estaduais. A autonomia e flexibilidade quanto 0 planejamento das aulas executadas foram elementos essenciais para 0 delineamento do estudo. Intervenções educativas como essas são importantes para argumentar sobre a relevância da Educação Ambiental nos espaços não formais.

\section{Referências}

ANTUNES, A. M.; CUZ, MILHOMEM, V. R.; FARIA, MENEZES, J. C. N. Uso de Recursos Áudio-Visuais em Sala de Aula para Sensibilização da Comunidade Escolar contra as Drogas Psicotrópicas. Ensino, Saude e Ambiente, v. 4, n. 3, 2011.

ARAUJO, D. L. C.; FERNANDES, M. A. F. A estética fotográfica a favor da sensibilização ambiental: reflexão e prática. Revista Educação Ambiental em Ação. 2010.

BRASIL. Política Nacional de Educação Ambiental, Lei 9795. Diário Oficial da República Federativa do Brasil, Brasília, DF, 27 abr. 1999. Disponível em: <http://www.planalto.gov.br/ccivil 03/Leis/L9795.htm> Acesso em: 26 mai. 2019. 
CARVALHO, I. C. M.; GRUN, M. Hermenêutica e educação. In: FERRARO JUNIOR, L. A. (Org.). Encontros e Caminhos: formação de educadoras(es) ambientais e coletivos educadores. Brasília: MMA, Diretoria de Educação Ambiental, 2005. p.175-188.

CYSNEIROS-MATOS, C. H. et al. Utilização de modelos didáticos no ensino de entomologia. Revista de biologia e ciências da terra, v. 9, n. 1, 2009.

FERRARIS, A. O. Que medo! Mente e Cérebro, edição 183 - Abril 2008. Disponível em: <http://www2.uol.com.br/vivermente/reportagens/que medo imprimir.html> Acesso em: 27 de Outubro de 2018.

FREIRE, P. A importância do ato de ler. São Paulo: Cortez/Autores Associados, 1985.

FREIRE, P. Pedagogia da Autonomia: saberes necessários à prática educativa. São Paulo: Paz e Terra, 1996.

GALHEIGO, C. B. S.; SANTOS, G. M. M. Saberes dos visitantes do zoológico de Salvador - BA sobre a fauna nativa e sua conservação. Revista Eletrônica do Mestrado em Educação Ambiental, vol. 23, p. 515-530, 2009.

GIBSON, J. J. The ecological approach to visual perception. Boston: Houghton Mifflin, 1979.

GOLDSCHMIDT, A. I. et al. A importância do lúdico e dos sentidos sensoriais humanos na aprendizagem do meio ambiente. Anais do XIII Seminário Internacional de Educação, 2008.

GUIMARÃES, M. et al. Educadores ambientais nas escolas: as redes como estratégia. Cadernos Cedes, Campinas, v. 29, n. 77, p. 49-62, 2009.

HOEFFEL, J. L.; FADINI, A. A. B. Percepção ambiental. In: FERRARO JUNIOR, L.A. (Org.). Encontros e Caminhos: formação de educadoras(es) ambientais e coletivos educadores. Vol 2. Brasília: MMA, Diretoria de Educação Ambiental, 2007. p 253-262.

INGOLD, T. Da transmissão de representações à educação da atenção. Educação, v. 33, n. 1, 2010.

JACOBI, P. R. Educação Ambiental, cidadania e sustentabilidade. Cadernos de pesquisa, n. 118, p. 189-205, 2003.

JARA, F. La miel y el aguijón. Taxonomía zoológica y etnobiología como elementos em la definición de las nociones de género entre los Andoke (Amazonia colombiana) Journal de la Société des Américanistes, v. 82, p. 209-258, 1996.

JUSTINA L. A. D. et al. Modelos didáticos no ensino de Genética. Anais do Seminário de extensão da Unioeste, 3., 2006. 
KUNIEDA, E. Espaços educadores no contexto do CESCAR (Coletivo Educador de São Carlos, Araraquara, Jaboticabal e Região/SP): do conceito à formação em Educação Ambiental. 2010. 145 f. Tese (Doutorado em Ciências, área de concentração em Ecologia e Recursos Naturais) - Centro de Ciências Biológicas e da Saúde, Universidade Federal de são Carlos, São Carlos, 2010.

LUDKE, M.; ANDRÉ, M. E. D. A. Pesquisa em educação: abordagens qualitativas. São Paulo: EPU, 1986.

MILLER, J. R. Biodiversity conservation and the extinction of experience. Trendsin Ecology and Evolution, v. 20, n. 8, p. 430-434, 2005.

MINAYO, M. C. S. (org.). Pesquisa Social. Teoria, método e criatividade. 14 ed. Petrópolis: Vozes, 1994.

MIRANDA, J. A. S.; FIGUEIREDO, R. A. Percepção e valores dos insetos no ensino fundamental de escola pública em Araraquara, SP. Anais do V EPEA Encontro Pesquisa em Educação Ambiental. São Carlos: Ufscar, 2009. 15 p. Disponível $<$ http://www.epea.tmp.br/epea2009 anais/pdfs/plenary/T02.pdf>. Acesso em: 20 outubro 2018.

MORALES, A. G. Educação Ambiental: somente a paixão levará a preservação. Revista Eletrônica do Mestrado em Educação Ambiental v. 3, jul/ago/set. 2000.

MORAN, J. M. Integração das Tecnologias na Educação. Desafios da televisão e do vídeo à escola. Secretaria de Educação a Distância, SEED. 2005.

RODRIGUES, P. et al. Materiais biológicos como instrumentos de ensino e aprendizagem em Biologia: construindo experiências formativas. Anais do $X$ Encontro de Extensão e IX Encontro de Iniciação à Docência, João Pessoa, PB, 2008.

RODRIGUES, W. C. et al. Metodologia científica. Faetec/IST. Paracambi, p. 220, 2007.

SCHUELTER, G. et al. Capacitação de professores em Educação Ambiental: uma proposta utilizando a internet. Florianópolis: UFSC, 2001.

SILVA, R. M. O Relicário de Celeida Tostes. Dissertação de mestrado. Centro de Pesquisa e Documentação de História Contemporânea do Brasil - CPDOC. Rio de Janeiro, 2006.

SILVEIRA, L. S.; ALVES, J. V. O uso da fotografia na Educação Ambiental: tecendo considerações. Pesquisa em Educação Ambiental, v. 3, n. 2, p. 125146, 2008.

TAFNER, M. A.; FISCHER, J. 0 cérebro e o corpo no aprendizado. Indaial: ASSELVI, 2004. 
THIEMANN, F. T. Biodiversidade como tema para a Educação Ambiental: contextos urbanos, sentidos atribuídos e possibilidades na perspectiva de uma Educação Ambiental crítica. 2013. 159 f. Tese (Doutorado em Ecologia e Recursos Naturais) - Centro de Ciências Biológicas e da Saúde, Universidade Federal de São Carlos, São Carlos, 2013.

THIEMANN, F. T.; OLIVEIRA, H. T. Biodiversidade: sentidos atribuídos e as contribuições do tema para uma Educação Ambiental crítica. Pesquisa em Educação Ambiental, v. 8, p. 114-128. 2013.

WHYTE, W. F. Sociedade de esquina: a estrutura social de uma área urbana pobre e degradada. Tradução de Maria Lucia de Oliveira. Rio de Janeiro, Jorge Zahar, 2005.

YIN, R. K. Pesquisa qualitativa do início ao fim. Porto Alegre: Penso, 2016. 